\title{
RATIONALITY, NORMS AND INSTITUTIONS: IN SEARCH OF A REALISTIC UTOPIA
}

\author{
BART ENGELEN
}

\begin{abstract}
The main goal of political philosophers is to search for a realistic utopia by taking individuals as they are and institutions, rules and laws as they might be. Instead of trying to change either individuals or institutions in order to improve society, this article argues that both strategies should be combined, since there are causal connections running both ways. Because individuals ultimately devise and uphold institutions, one should be optimistic about the possibilities of deliberately improving society through institutional reforms. However, one should adequately model the influences that these reforms have on individuals, their identities and their motivations. From the fact that individuals can actually turn into egoists if they are treated as such, this article stresses the need to detect and maintain non-egoistic motivations. Since informal norms, for example, motivate individuals to socially desirable action, it is important to devise formal institutions that support rather than erode norm-guided behavior.
\end{abstract}

Keywords: Rationality; norms; institutions; crowding-out effects.

\section{Rationality, Norms and Institutions: In Search of a Realistic Utopia}

The main goal of political philosophers is to search for what has been labeled a "realistic utopia" (Rawls 1999, 12). In this respect, they often refer to Jean-Jacques Rousseau (1983 [1762], 17) who explicitly aims "to inquire whether there can be some legitimate and sure rule of administration in the civil order, taking men as they are and laws as they might be". Since it concerns a utopia, one tries to conceive of the world and its institutions as they ought to look like in some ideal situation. By adding the term realistic, one avoids the implication that such a utopia refers to an inherently impossible, unrealizable or at least impractical ideal. This perfectly corresponds to what Pettit $(2002,275)$ labels

the two most central challenges in social and political theory (...): first, to identify the sorts of public institutions that have best claim to be regarded as desirable; and, second, to demonstrate that those institutions are feasible, showing how they can be introduced and maintained among ordinary, unsaintly human beings.

In this article, I want to analyze more fully how to model both institutions and individuals if one wants to embark on this normative journey. 


\section{Two Routes towards a Better Society}

In general, there are two strategies to improve the world. A useful analogy here can be made by comparing social life to a game in which the players have to abide by certain rules. First, there is the option-mostly taken by moral philosophers-of trying to improve (the moral quality of) the players. In this view, one should focus on the motivations of the players, for example by eliciting fairness and honesty rather than pure opportunism. Second, there is the option-mostly taken by political philosophers and economists - of trying to improve the rules of the game. Since the first route is long and full of obstacles-it is not easy and perhaps even morally questionable to try and change people in some deliberate way one can focus on the rules and institutions that guide and coordinate social interaction. The quest for a realistic utopia is thus based on the optimistic conviction that individuals are to some extent able to choose the rules of their society and thus to shape their own future.

The basic question of this article is thus the central one within ethics, which Paul Ricoeur $(1990,202)$ defines as "la visée de la "vie bonne" avec et pour autrui dans des institutions justes". Whereas the first route focuses on the individual level (la vie bonne), the second focuses on the institutional level (des institutions justes). In this article, I want to show that an all too strict dichotomization between both strategies is inappropriate. In my view, both are valid and should be combined. Instead of defending the current division of tasks between moral and political philosophers, I believe a joint effort is needed, since there are causal connections between individuals and rules that are running both ways. First, individuals change institutions. In the end, it is the players themselves who agree on a particular set of rules. While rules are inherited from past generations, they ultimately stem from individuals, their actions, beliefs and preferences. And while changing these institutions is typically an incremental and thus long-term process, it is the individuals themselves that can modify, rearrange or even do away with these institutions. Second, and this is often overlooked, institutions also change individuals. Among the numerous influences on the beliefs, preferences and motivations of individuals are their social milieu, the moral and cultural norms present in their society and the institutional context they live in.

\section{Two Models of Individuals and Institutions}

Norms, rules and institutions are crucial to understand the problems with which modern societies are confronted. Within the social sciences, the conventional way of posing the basic issue starts by modeling citizens as rational beings. The dominant conception of rationality is the economic one, according to which an individual is rational if he chooses the action of which he thinks will best serve his 
self-interest. In this view, it is in each individual's interest to freeride on the contributions of others, which effectively inhibits collective action to occur.

The traditional solution to such social dilemmas is to impose on all citizens rules that compel citizens to contribute to the provision of some public good. Norms, rules, laws and institutions are understood as means towards the realization of social order and mutually beneficial outcomes. They appear as external interventions that guide what one might call 'societal traffic'. In this view, institutions-like traffic rules-aim to make sure that social interactions result in mutually beneficial (or at least not detrimental) outcomes.

Conventional thinking on the role of norms and institutions thus analyzes these as external interventions that limit the range of options that people have or alter the payoffs of these options. This allows economists to understand norm-guided behavior in purely calculating and instrumental terms. However, attempts like these are unconvincing, since they do not take into account the fact "that people often follow norms even when external sanctions are not a credible threat" (Ben-Ner, Putterman 1998, 283). After a process of internalization-through education, socialization and sanctioning - norms typically have an additional, more internal impact on behavior. If people identify with a norm, this turns into a reason which can genuinely motivate them to act against their self-interest.

The economic conception of rationality is thus inadequate to understand normguided behavior. People who act upon a norm are not primarily concerned with the consequences of their behavior. They act as they do, because they think it is the right thing to do, not because they think it is best means to a certain goal. In contrast with the forward-looking nature of instrumental actions, norm-guided behavior is thus typically backward-looking. Take the example of a norm of fairness, according to which people should contribute to the public good if others do their fair share as well. Friends typically all want to do the dishes, even if this leads to a full kitchen and thus to an inefficient way of working (Elster 1989, 5657). This kind of behavior is clearly not instrumental in nature.

Here, a dilemma arises. One can either choose to hold on to the conventional, economic conception of rationality and conclude that norm-guided behavior is irrational, or try to construct an alternative conception of rationality. In what I call an expressive conception of rationality, an individual is rational if he acts on the basis of preferences with which he identifies. This allows one to understand norm-guided behavior as rational, namely to the extent that the individual has internalized the norm at hand. This also avoids the counterintuitive conclusion that only a minority of people are rational, namely those who consistently try to serve their self-interest.

In this expressive conception of rationality, norm-guided behavior is understood as the expression of one's identity and thus of the fact that one conceives of oneself as belonging to a particular group. In this view, norms are informal guidelines that specify which behavior is appropriate within this group. It is crucial to see that they mutually support more formal ways of regulating behavior through external 
sanctions (Bowles, Gintis 2003, 439). While social norms reduce the need of formal institutions, they complement rather than substitute each other: "it is widely held that strong social norms reduce the burden on law enforcement; that laws supported by social norms are likely to be significantly more enforceable; and that laws that are formulated in ways that are congruent with social norms are much more likely to be enacted than laws that offend such norms" (Etzioni 2000, 159). This way, one can understand how internalized norms can be the basis of rational, free and voluntary behavior that in general is prosocial and beneficial from a societal point of view. ${ }^{1}$

\section{Why a Realistic Model of Individuals and Institutions is Needed}

The conventional, economic model of individuals stresses that people, even in their public roles as citizens, civil servants or politicians, should be modeled as trying to serve their self-interest. In designing the institutions that guide social interaction, the argument goes, it is best not to assume benevolence. In this respect, one often quotes David Hume (1963 [1741], 42) who argues that "in contriving any system of government and fixing the several checks and controls of the constitution, every man ought to be supposed a knave and to have no other end, in all his action, than private interest". This assumption of universal egoism is said to be the appropriate one, even if it is proven that not all real-world individuals are purely self-interested. Institutional schemes are not to be evaluated on the basis of what their consequences would in fact be, but on the basis of what their consequences would be if everyone were a knave. After all, it makes sense to lock your door even if you think that only a fraction of all people are thieves.

Next to the abovementioned criticism that this model is clearly inadequate to describe and explain individual behavior, I want to argue that it is inapt for normative purposes as well. The reason is as straightforward as it is simple:

...if the outcomes of institutions designed for knaves are much worse than the outcomes designed for actual individuals and the odds of everybody being a knave were low, then it would be foolish to choose the institutions designed for knaves (Hausman 1998, 4).

Normative issues should therefore not be decided upon the obviously false claim that individuals are driven solely by self-interest. If individuals, their interests, preferences and values do matter at all, institutional reform should be based on empirically adequate and realistic models of these elements.

\footnotetext{
1 It might be raised that norms do not necessarily prescribe prosocial behavior. However, norms that do will generally improve the fitness of the group and will thus be favored by natural selection: "groups with prosocial internal norms will outcompete groups with antisocial, or socially neutral, internal norms" (Bowles, Gintis 2003, 440).
} 
Theorists who consider the assumption of universal egoism to be appropriate for normative purposes, even if it turns out to be false, are inevitably making claims about real-life individuals if they want their arguments in favor of some institutional setting to have any force at all. The argument that governments are to be constrained because they allow self-interested individuals to exploit others is relevant only if realworld individuals do indeed act egoistically. The same holds for the argument that markets are desirable because they allow self-interested individuals to achieve mutually beneficial arrangements. However, if one claims that individuals are really egoistic, one should also recognize that this can cause social interactions to go awry as well. In the case of negative externalities, for example, it causes markets and governments to fail and divert from the ideal situation (Buchanan 1995, 22).

If one should take individuals as they are when trying to improve society, as I believe one should, it is reasonable to adopt some policy on a realistic estimate of the proportion of the population that acts in a purely egoistic manner. By taking into account the reactions of only the opportunistic citizens, however, one risks making everyone worse off. In my view, there are two reasons why this is so. First, there is the fact that this is likely to lead to a proliferation of rules that have to be enforced through costly incentive schemes. The only solution for a world full of freeriders lies in a large bureaucratic apparatus that soaks up a lot of money and liberties. However, while it makes sense to close your door when leaving the house, few people will turn their homes into fortresses, even though this seems to be the right thing to do if you assume that everyone is out to steal your possessions. Second, one needs to take into account that the institutions one devises have an impact on all citizens living there. The project of designing the institutions for a whole society is a completely different issue than that of leaving the house. In what follows, I want to explain this last thought more fully.

\section{The Normative Repercussions of a Realistic Model of Individuals and Institutions}

According to Philip Pettit, there are two main strategies for devising rules and institutions. First, there is the motivating strategy that tries to achieve compliance of individual citizens by rigging the payoffs. From the assumption that egoism motivates people to freeride, one concludes that rules and institutions should be organized in such a way that compliance becomes more attractive in self-interested terms. However, since individuals differ in the extent to which they comply, "the suggestion in this strategy, then, is that we should look to the most self-interested person we can imagine - the knave, in traditional parlance-and make sure that that agent will face penalties that are harsh enough, or rewards that are high enough, to elicit compliance with the institution in question" (Pettit 2002, 276). As I have shown above, this is how political philosophers and economists typically view the role of norms and institutions. 
This strategy faces the problem that a lot of people comply with rules and institutions on a spontaneous basis. As I have shown, non-egoistic motivations, like an internalized prosocial norm, often motivate people to comply even if this goes against their self-interest. ${ }^{2}$ Moreover, introducing sanctions apt for knaves can have a destructive impact on such non-egoistic motivations. As a result, it may actually reduce the level of overall compliance rather than increase it. Because it makes egoistic considerations more salient than before, this strategy can induce people to start reasoning like a knave even if they did not do so before. Treating citizens and politicians as untrustworthy knaves can thus work as a self-fulfilling prophecy (Pettit 2002, 295). Punctual workers can become clock-watchers with lower work morale if one starts to impose harsh penalties for being late at the office. The same mechanism occurs with "children who are paid by their parents for mowing the family lawn. Once they expect to receive money for that task, they are only willing to do it again if they indeed receive monetary compensation" (Frey, Jegen 2001, 596).

In what follows, I want show how this mechanism is present in the workings of both markets and governments. Traditionally, the market is thought of as a neutral mechanism allocating resources, incomes, goods and services in ways that do not fundamentally affect the individuals interacting there. Indeed, it is renowned and praised for its 'invisible hand' mechanism, which stresses that the market tends to produce socially desirable outcomes without changing the motivations of the individuals. One need not rely on the benevolence of the butcher (or change him into a benevolent person) to buy the meat one wants. In contrast-or better, in addition-I want to stress the insight of institutional economists that the market has a fundamental impact on the motivations and identities of individuals interacting there (Hodgson 1988, 173-179). Since it rewards egoistic behavior, the market can be said to bring about egoistic individuals: "it has been suggested that homo economicus produced capitalism, meaning roughly that human nature being what it is, the evolution of the capitalist rules of game is both likely and desirable. But this may be just backwards, or at least one-sided; one could equally argue that capitalism produced homo economicus" (Bowles, Gintis 1993, 97). In this respect, one can speak of a crowding-out effect, which means that institutions can cause egoistic considerations to outweigh other considerations.

Like markets, governments can crowd out more noble motivations by rewarding and thus reinforcing egoistic motivations as well. Politico-legal rules that are based on the general principle that citizens are not to be trusted can have an erosive impact on the extent to which they are upheld: "a constitution implying a fundamental distrust of its citizens, and seeking to discipline them, tends to crowd

2 There is a whole range of literature on the so-called phenomenon of negative strong reciprocity or altruistic punishment, which refers to the tendency of a majority of people to punish the violation of norms in conditions where this entails no personal benefit whatsoever (Bowles, Gintis 2003). 
out civic virtue and undermines the support which citizens are prepared to give towards the basic laws" (Frey, Jegen 2001, 604). It is crucial to stress that such crowding-out effects have been proven to be empirically relevant: "external intervention via monetary incentives or punishments may undermine, and under different identifiable conditions strengthen, intrinsic motivation. (...). There exist a large number of studies in, offering empirical evidence in support of the existence of crowding-out" (Frey, Jegen 2001, 589).

Because of these problems for the motivating strategy, Pettit $(2002,277)$ puts forward a second strategy, namely the managing strategy, which is based on an explicit recognition of the fact that a majority of people are not full-blooded opportunists at all. Here, one tries to detect, support and reinforce non-egoistic motivations, which help achieve social order and cooperation. Only after getting the most out of the citizens who voluntarily comply, will one aim one's arrows at more self-interested citizens. Of course, these should still be motivated through welltargeted sanctions that send a strong signal that freeriding behavior does not pay off.

This strategy also suggests the use of screening procedures that aim to select for public offices those people who are likely to serve the public good more or less spontaneously (Pettit 2002, 297-298). Indeed, one should try to allocate individuals with different motivations in ways that best promote the public good. In this respect, Pettit $(1996,81)$ refers to James Madison, who argues in his Federalist Paper no. 57 that "the aim of every political constitution is or ought to be first to obtain for rulers men who possess most wisdom to discern, and most virtue to pursue the common good of the society; and in the next place, to take the most effectual precautions for keeping them virtuous, whilst they continue to hold their public trust". In order to reach a socially desirable institutional scheme, it is crucial to detect, make use of and actively support such public-spirited motivations. ${ }^{3}$

Treating politicians and civil servants as egoistic, for example by raising their salaries (as the motivating strategy would recommend), will attract more selfinterested money-seekers rather than people who voluntarily want to serve the public interest. Here too, the assumption of egoism functions as a self-fulfilling prophecy, which in the end leads to a situation that is worse than it initially was or than it could be. The strategy of turning one's home into a fortress might actually be counterproductive, because this tends to attract even more thieves.

As people are typically motivated by a mix of both egoistic and other motivations of which the relative weight varies from individual to individual and from context to context, it is important to rely on a combination of both the motivating and the managing strategy. While exclusively relying on monetary incentives can have negative effects, a complete absence of sanctions tends to

\footnotetext{
3 This interpretation of the general spirit of the Founding Fathers could not diverge more from the standard economist's interpretation, according to which they favor strong constitutional restrictions to keep egoistic politicians in check.
} 
corrupt as well. Well-targeted sanctions can support rather than erode non-egoistic motivations. Nevertheless, as should be clear by now, the managing strategy shows the route to follow if one thinks that normative arguments in favor of some institutional scheme should take individuals as they actually are: "the considerations presented show why the managing strategy ought to be much more attractive than the more traditional, motivation strategy. The managing strategy would give us a world fit for ordinary, more or less virtuous people, the motivating strategy would give us a world fit for knaves" (Pettit 2002, 305).

The thought that political philosophers and economists should model individuals as they actually exist has led them to take individuals and preferences as given (Cohen 2002, 368). If one wants to assess the impact of institutional reforms, the argument goes, one should assume that individuals stay the same in different contexts. Otherwise, one cannot ascribe the resulting changes to these reforms. As I have already suggested, the problem with this assumption of exogenously given preferences is that individuals become who they are and want to be partly because of their social and institutional environment. These influences should be taken into account when thinking about desirable rules and institutions.

To be sure, this does not contradict the claim that people should be modeled as they are. A realistic model of individuals is not the same as a completely static description. Joshua Cohen, who joins Rawls in his search for a realistic utopia, gives two reasons why institutions are important:

"a first reason is that institutions play a large role in shaping economic and political outcomes, given preferences (...). The second reason is that institutions play a large role in shaping a society's culture and the identity of members" (Cohen 2002, 381).

Attempts to improve society should be based on this two-fold insight. If one wants to propose institutional reforms, one needs to assess beforehand their potential impact on individuals. Precisely because one ought to model individuals adequately, should one pay attention to the ways in which they are formed by their environment.

\section{Conclusion}

Since the ultimate goal of political philosophers and economists is to come up with alternative visions of what the world might look like, they should always believe that it is possible to actually improve things. After all, such a deliberate and conscious effort to make the world a better place is precisely what politics is all about. In this respect, I totally agree with Winston Churchill: "for myself, I am an optimist-it does not seem to be much use being anything else" ${ }^{4}$. In contrast with

\footnotetext{
4 Winston Churchill in a speech at the Lord Mayor's banquet on November 9, 1954.
} 
Churchill, I have not offered specific policy options or institutional arrangements to improve the world. Nevertheless, I hope this article contains some useful suggestions with regard to the routes one ought to follow in search of a realistic utopia. It is up to policy makers and their advisors to apply the insights of political philosophers and economists at the pragmatic level of real-world politics.

\section{References}

Ben-Ner, A., Putterman, L. (Eds.). Economics, Values, and Organization. Cambridge: Cambridge University Press, 1998.

Bowles, S., Gintis, H. The Revenge of Homo Economicus: Contested Exchange and the Revival of Political Economy. Journal of Economic Perspectives 7, 83-102, 1993.

Bowles, S., Gintis, H. Origins of Human Cooperation. In P. Hammerstein (Ed.). Genetic and Cultural Evolution of Cooperation. Cambridge (Massachusetts): The MIT Press, 429-43, 2003.

Buchanan, A. Ethics, Efficiency, and the Market. Oxford: Clarendon Press, 1995.

Cohen, J. Taking People as They Are? Philosophy and Public Affairs 30, 363-86, 2002.

Elster, J. Nuts and Bolts for the Social Sciences. Cambridge: Cambridge University Press, 1989.

Etzioni, A. Social Norms: Internalization, Persuasion, and History. Law and Society Review 34, 157-78, 2000.

Frey, B.S., Jegen, R. Motivation Crowding Theory. Journal of Economic Surveys 15, 589-611, 2001.

Hausman, D.M. Rationality and Knavery. In W. Leinfellner , E. Köhler (Eds.). Game Theory, Experience, Rationality. Foundations of Social Sciences, Economics and Ethics in Honor of John C. Harsanyi. Dordrecht: Kluwer, 67-79, 1998.

Hodgson, G.M. Economics and Institutions: A Manifesto for a Modern Institutional Economics. Cambridge: Polity Press, 1988.

Hume, D. Essays, Moral, Political and Literary. Oxford: Oxford University Press, 1963 [1741].

Pettit, P. Institutional Design and Rational Choice. In R.E. Goodin (Ed.). The Theory of Institutional Design. Cambridge: Cambridge University Press, 54-89, 1996.

Pettit, P. Rules, Reasons, and Norms. Oxford: Clarendon Press, 2002.

Rawls, J. The Law of Peoples. Cambridge: Harvard University Press, 1999.

Ricoeur, P. Soi-męme comme un autre. Paris: Seuil, 1990.

Rousseau, J.-J. On the Social Contract; Discourse on the Origin of Inequality; Discourse on Political Economy. Translated by D.A. Cress and introduced by P. Gay. Indianapolis: Hackett Publishing Company, 1983 [1762].

Centre for Economics and Ethics

K. U. Leuven, Naamsestraat 69 ,

3000 Leuven, Belgium

Tel.: +32 16325721

E-mail: bart.engelen@econ.kuleuven.be 